\title{
Risk factors associated with acquiring superficial fungal infections in school children in South Western Nigeria: a comparative study.
}

\author{
Olaide Oke Olutoyin ${ }^{1}$, Olaniyi Onayemi², Akinlolu Omisore Gabriel ${ }^{3}$
}

1. Federal Medical Centre, Abeokuta, Nigeria, Dermatology unit, Department of Internal Medicine

2. Obafemi Awolowo University, Ile-Ife, Nigeria, Department of Dermatology and Venereology

3. Osun State University, Osogbo, Nigeria, Department of Community Medicine

\begin{abstract}
Introduction: Superficial fungal infections (SFI) are caused mainly by dermatophytes and yeasts. SFI is of major public health concern and is a common cause of skin disease among school children.

Objectives: The aim of this study was to identify the risk factors associated with acquiring superficial fungal infections in school children in Ile-Ife, South West Nigeria as this will assist in instituting appropriate interventions.

Methods: A total of 560 children; 280 with superficial fungal infections as subjects and 280 age and sex matched school children as controls were recruited through multistage sampling method from 10 primary schools (private and public owned) in Ile-Ife, Nigeria.

Discussion: Pupils were aged 5-16 years with a mean age of 9.42 \pm 2.00 . Risk factors documented in this study included poor living conditions, use of barbers' clippers, low socio-economic status, poor hygiene, attendance of public schools and not living with both parents. The last four factors remained significant on binary logistic regression.

Conclusion: The study shows that the risk for acquiring superficial fungal infections remains high in school children and in communities with low socio-economic positions.

Keywords: Risk factors, school children, skin, superficial fungal infections.

DOI: https://dx.doi.org/10.4314/ahs.v17i2.6

Cite as: Olutoyin OO, Onayemi $O$, Gabriel AO. Risk. factors associated with acquiring superficial fungal infections in school children in South Western Nigeria: a comparative study. Afri Health Sci. 2017;17(2): 330-336. https:/ / dx.doi.org/10.4314/ahs.v17i2.6
\end{abstract}

\section{Introduction}

Superficial fungal infections (SFI) of the skin describe fungal infections that affect the outer layers of the skin, the nails and the hair and these are caused mostly by dermatophytes or yeasts and rarely by non-dermatophyte moulds. ${ }^{1}$ Though they rarely cause illness, they are often chronic or recurrent in their course. ${ }^{1}$ SFI is a common cause of skin disease worldwide and poses a major public health concern especially among school children. There are regional characteristics and predispositions to devel-

\section{Corresponding author: \\ Olaide Oke Olutoyin, \\ Dermatology Unit, Department of Internal \\ Medicine, Federal Medical Centre, Abeokuta \\ Formerly at: Department of Dermatology and \\ Venereology, Obafemi Awolowo University, Ile-Ife, \\ Nigeria \\ Email: laidekolawole@yahoo.com}

opment of SFI and this has been documented by some studies. ${ }^{2,3}$

Though some studies have documented high prevalence of SFI among Nigerians, there is no recent data among the population studied to know current trends. Also, only few of the previous studies did a comparative study that involved pupils with SFI and controls while also comparing risk factors for acquiring SFI between public schools and privately owned schools. Furthermore, risk factors for acquiring SFI among school children have not been extensively documented. It is therefore imperative to identify the factors that predispose to the development of SFI so as to provide evidence-based and effective preventive measures, thus reducing the prevalence and the attendant morbidity associated with superficial fungal infections and this was our aim in this present work.

\section{Methods}

A cross sectional study was conducted that involved 280 pupils (subjects) with SFI and another 280 pupils who 
served as age and sex matched controls. They were selected through multistage random sampling from 10 schools (6 publicly owned and 4 privately owned) in Ile-Ife, South-Western Nigeria between January and March 2011. Selection of study participants was done via a multistage sampling technique that involved selection along local governments, schools (both public and private), classes and proportionate pupils from selected class strata. After clinical diagnosis of cases of SFI by the principal investigator, skin scrapings (or nail clippings where indicated) for fungal microscopy and culture were done for the pupils with tinea infections and those who were culture positive were then included in the study. Subsequently, one control (a respondent without SFI) who was of the same age and sex as the identified respondent (subject) with SFI in the same class was chosen via balloting from the pool of respondents who were of the same age and sex, thus for each case of SFI seen, one age and sex matched control was chosen, making equal number of subjects and controls.

Informed consent from parents/guardians of all pupils involved in the study was obtained, pupils whose parents did not give consent and pupils who did not assent were not included in the study. Permission was taken from Osun State Ministry of Education, local inspectorates of education at the local government levels and school authorities. Ethical clearance was obtained from Obafemi Awolowo University Teaching Hospital, Ile-Ife before commencement of study.

All pupils recruited were interviewed and socio-demographic characteristics were obtained. History to identify predisposing factors was also obtained. Socio-economic status of their parents was determined using the modified wealth index. ${ }^{4,5}$ Household living conditions were determined using the Canadian crowding index that defines crowded housing as requiring one or more additional bedrooms. ${ }^{6}$ The study participants were examined by same dermatologist using natural light in a private room within the school premises for the presence of any SFI. Their level of hygiene was assessed using the hygiene assessment tool. ${ }^{7}$ Skin scrapings and nail clippings were done for clinically suspected SFI and sent for microscopy and culture.

Data entry and processing was carried out using SPSS version 16 software (SPSS Inc Chicago, Illinois, USA). Chi square test was used as a test of association. A p value of $\leq 0.05$ was taken as significant. We also carried out a multivariate analysis (logistic regression) to identify independent factors associated with SFI. Only variables that were significant on bivariate analysis (chi square) were put in the logistic regression models and this was done at two different levels, socio-demographic variables on one hand and behavioral variables on the other hand.

\section{Results}

A total of 560 pupils were included in the study. 280 pupils who had clinical evidence of SFI and 280 pupils who were age and sex matched controls. Tables $1 \mathrm{a} \& 1 \mathrm{~b}$ show the socio-demographic characteristics of the pupils and the presence of superficial fungal infections. The variables; socio-economic status, ethnicity, school type, class and living arrangement were all found to be statistically significant.

Table 1a: Socio-demographic (age and sex) characteristics of the pupils with SFI (Subjects and controls)

\begin{tabular}{|l|l|l|l|l|}
\hline \multirow{2}{*}{ Variable } & \multicolumn{3}{|l|}{$\begin{array}{l}\text { Pupils with Superficial fungal } \\
\text { infections (Subjects) }\end{array}$} & \multicolumn{2}{l|}{$\begin{array}{l}\text { Pupils without Superficial fungal } \\
\text { infections (Controls) n = 280 }\end{array}$} \\
\cline { 2 - 5 } & Frequency (n) & $\begin{array}{l}\text { Percentage } \\
(\%)\end{array}$ & Frequency (n) & $\begin{array}{l}\text { Percentage } \\
(\%)\end{array}$ \\
\hline Age in years & & & & \\
\hline $5-8$ & 94 & 33.6 & 94 & 33.6 \\
\hline $9-12$ & 164 & 58.6 & 164 & 58.6 \\
\hline $13-16$ & 22 & 7.8 & 22 & 7.8 \\
\hline Total & 280 & 100.0 & 280 & 100.0 \\
\hline Sex & & & & 59.3 \\
\hline Male & 166 & 59.3 & 166 & 40.7 \\
\hline Female & 114 & 40.7 & 114 & 100.0 \\
\hline Total & 280 & 100.0 & 280 & \\
\hline
\end{tabular}


Table 1b: Other socio-demographic characteristics of the pupils and the presence/ absence of superficial fungal infections

\begin{tabular}{|c|c|c|c|c|c|}
\hline \multirow[t]{2}{*}{ Variable } & & \multicolumn{2}{|l|}{ SFI } & \multirow{2}{*}{$\begin{array}{l}\text { Total. } \\
n=560\end{array}$} & \multirow[t]{2}{*}{ Remark } \\
\hline & & $\begin{array}{l}\text { Subjects } \\
(\%) \\
\text { n=280 }\end{array}$ & $\begin{array}{l}\text { Controls } \\
(\%) n=280\end{array}$ & & \\
\hline \multirow{5}{*}{$\begin{array}{l}\text { Socio- } \\
\text { Economic } \\
\text { Status } \\
\text { (SES) } \\
\text { Ethnicity }\end{array}$} & Low SES & \multicolumn{2}{|c|}{$186(60.8) \quad 120(39.2)$} & 306 & \multirow{2}{*}{$\begin{array}{l}\chi^{2=} 31.385 \\
p<0.001\end{array}$} \\
\hline & High SES & $94(37.0)$ & $160(63.0)$ & 254 & \\
\hline & Yoruba & $265(51.1)$ & $254(48.9)$ & 519 & \multirow{2}{*}{$\begin{array}{l}\chi^{2}=8.300 \\
p=0.040\end{array}$} \\
\hline & Hausa & $7(50)$ & $7(50)$ & 14 & \\
\hline & Igbo & $2(13.3)$ & $13(86.7)$ & 15 & \\
\hline \multirow{5}{*}{$\begin{array}{l}\text { School } \\
\text { Type } \\
\text { Class* }\end{array}$} & Others & $6(50.0)$ & $6(50.0)$ & 12 & \multirow{5}{*}{$\begin{array}{l}\chi^{2}=38.81 \\
p_{2}<0.001 \\
\chi^{2}=4.864 \\
p=0.027\end{array}$} \\
\hline & Public & $205(60.5)$ & $134(39.5)$ & 339 & \\
\hline & Private & $75(33.9)$ & $146(66.0)$ & 221 & \\
\hline & Lower primary school & $139(45.7)$ & $165(54.3)$ & 304 & \\
\hline & Higher primary school & $141(55.1)$ & $115(44.9)$ & 256 & \\
\hline \multirow[t]{3}{*}{ Religion } & Christianity & $213(49.3)$ & $219(50.7)$ & 432 & \multirow{2}{*}{$\begin{array}{l}\chi^{2}=0.365 \\
p=0.546\end{array}$} \\
\hline & Islam & $67(52.3)$ & $61(47.7)$ & 128 & \\
\hline & Living with both parents & $148(41.0)$ & $213(59.0)$ & 361 & \multirow{2}{*}{$\begin{array}{l}\chi^{2}=32.935 \\
p<0.001\end{array}$} \\
\hline \multirow{3}{*}{$\begin{array}{l}\text { Living } \\
\text { arrangeme } \\
\text { nt } \\
\text { Household } \\
\text { living } \\
\text { condition }\end{array}$} & $\begin{array}{l}\text { Not living with both } \\
\text { parents }\end{array}$ & $132(66.3)$ & $67(33.7)$ & 199 & \\
\hline & Uncrowded & $130(47.8)$ & $142(52.2)$ & 272 & $\chi^{2}=1.040$, \\
\hline & Crowded & $150(52.1)$ & $138(47.9)$ & 288 & $\mathrm{p}=0.594$ \\
\hline
\end{tabular}

*Lower primary school (Years 1 to 3), Upper primary school (Years 4 to 6).

Table 2 shows the behavioral characteristics of the pupils fungal infections. These were poor hygiene, involvement that were statistically significant in acquiring superficial in gardening and use of barbers' clippers. 
Table 2: Behavioural characteristics of the pupils and the presence of superficial fungal infections *** $n=449$ because this is not applicable to those excluded,

N.B: Other behavioral characteristics (variables) which were not statistically significant were not included in this table. They include frequency of bath, allergy, use and frequency of use of occlusive clothes and shoes.

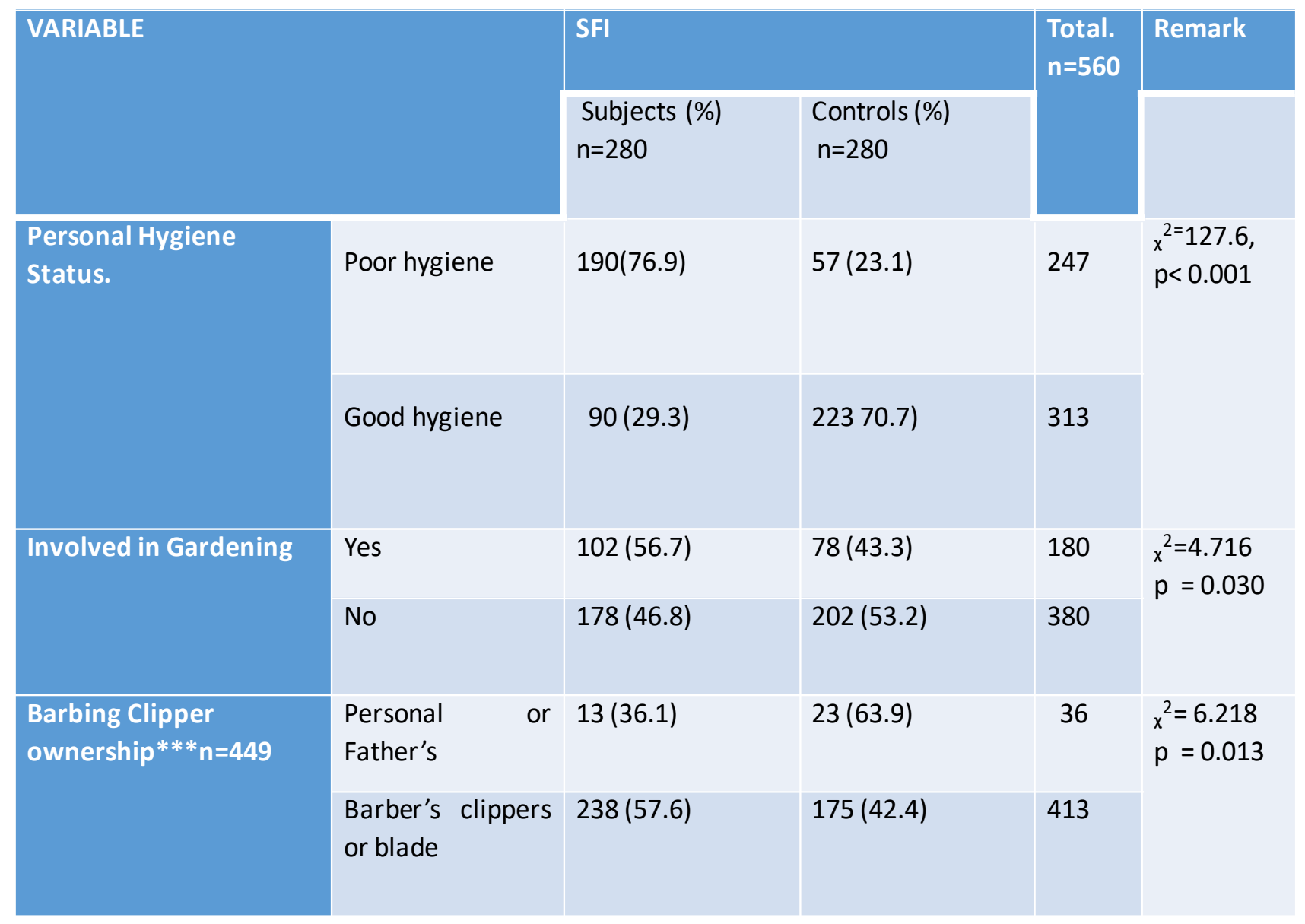

In Table 3, the variables; ethnicity and class were not statistically significant, however, attendance of private schools, high socio-economic status and living with both parents were protective socio-demographic factors against the development of SFI. Similarly, the variables involvement in gardening and ownership of clippers were not statistically significant, while good hygiene was a behavioral protective factor against the development of SFI. 
Table 3: Binary logistic regression of the outcome variable presence of superficial fungalinfections and its possible socio-demographic predictors. Variables in this model- Ethnicity; Type of school; Class; Socio-economic status; and Living arrangement.

\begin{tabular}{|c|c|c|c|c|c|}
\hline \multirow[t]{2}{*}{ Variable } & \multirow{2}{*}{$\begin{array}{l}\text { Categories of } \\
\text { variable. }\end{array}$} & \multirow{2}{*}{$\begin{array}{l}\text { Stat. } \\
\text { significance }\end{array}$} & \multirow[t]{2}{*}{ Odd's ratio } & \multicolumn{2}{|c|}{ 95\% Confidence interval } \\
\hline & & & & Lower & Upper \\
\hline \multirow[t]{4}{*}{ Ethnicity } & Yoruba (Reference) & 0.016 & & & \\
\hline & Hausa & 0.818 & 0.867 & 0.257 & 2.924 \\
\hline & Igbo & 0.073 & 6.088 & 0.845 & 43.866 \\
\hline & Others & 0.983 & 0.983 & 0.195 & 4.945 \\
\hline Type of School & Public (Reference) & $<0.001^{*}$ & 0.467 & 0.317 & 0.687 \\
\hline Class & $\begin{array}{l}\text { Lower primary school } \\
\text { (Reference) }\end{array}$ & 0.081 & 1.384 & 0.961 & 1.995 \\
\hline $\begin{array}{l}\text { Socio-economic } \\
\text { Status }\end{array}$ & Low (Reference) & $<0.001^{*}$ & 0.496 & 0.340 & 0.723 \\
\hline Living arrangement & $\begin{array}{l}\text { Living with both } \\
\text { parents (Reference) }\end{array}$ & $<0.001^{*}$ & 2.311 & 1.576 & 3.390 \\
\hline
\end{tabular}

\section{Discussion}

Our study identified certain factors as being significant for the development of superficial fungal infections. Superficial fungal infections that were studied included tinea capitis, tinea faciei, tinea corporis, tinea unguium, tinea manuum, tinea pedis and pityriasis versicolor. The factors associated with development of SFI included socio-demographic characteristics such as living with either parent rather than living with both parents, low socio-economic status, attendance of public school rather than privately funded school, and behavioral characteristics such as poor hygienic habits and use of barbers' clippers instead of personal clippers. These findings are comparable to previous studies done on possible risk factors for acquiring superficial fungal infections. ${ }^{8,910}$ In the study carried out by Akinboro et al in a community in Osogbo, Nigeria, they found risk factors for fungal infections to include crowded living conditions, poor sanitary conditions, visits to barbers' salon and use of their clippers and lastly, close contact with soil and animals. ${ }^{8}$ Similarly, Metintas et al in another study among pupils living in rural areas in Turkey, documented male gender, poor hygiene and history of contact as the main risk factors associated with acquiring SFI. ${ }^{9}$ Figueroa et al in their study on the risk factors for infection and carriage of tinea capitis in South Western Ethiopia found overcrowding not to be significantly associated with infection, just as it was in this study and also noted increased prevalence among the urban community rather than the rural community. Although it was not statistically significant, more people who live in crowded conditions had SFI than those who did not live in overcrowded homes in this study. The slightly higher prevalence of superficial fungal infections among pupils living in crowded populations compared to controls observed in this study was not as significant as in previously documented studies that showed that overcrowding promotes the spread of fungal infections. ${ }^{8,10}$

Considering the living arrangement, there were more pupils living with their parents among the controls (59.0\%) than among those with superficial fungal infections, this probably may be due to the fact that there may be better supervision of their health and effective care such as good personal hygiene, having regular baths, good personal grooming and good nutrition than if the child was living with just one of the parents, grandparents or any other family member.

Socio-economic status of parents has been one of the factors associated with presence of superficial fungal infections. Pupils with parents of low socio-economic status had been found to have increased prevalence of superficial fungal infections and vice versa. ${ }^{10,11}$ This was corroborated in this study as up to two thirds of the pupils with superficial fungal infection were of low socioeconomic status while up to two thirds of the pupils in the control group had parents of high socio-economic 
status. Poverty is one of the reasons why SFI remain a prevalent condition in our environment. Poorer people are likely to be less hygienic compared to people who are well to do.

Likewise, more pupils visiting the barbers' for their haircut had superficial fungal infection particularly tinea capitis than control cases, such was found in other studies including that by Soyinka in Ife, SouthWest Nigeria and Ogbonna in Jos, North central Nigeria. ${ }^{10,12,13}$ As was rightly noted by these studies, most of the salons used by the children have poor sanitary conditions. Moreover, the clippers are not adequately disinfected before use for another child; these promote the spread of the infection. Use of personal clippers reduced the chances of acquiring the infection in this study.

Pupils in public schools (government funded) had superficial fungal infection more significantly than the privately funded schools. This is corroborated by previously documented studies. ${ }^{10,14-16}$ Part of the explanation for this is that majority of the pupils in the public schools are of low socio-economic status as was also observed in this study with poor hygiene, malnutrition, overcrowding and poor general social conditions. These are significant risk factors for acquiring superficial fungal infections. ${ }^{16}$ Factors such as living conditions, socio-economic status, poverty, sanitary conditions at the barbers' shops are social determinants of health that influence the presence of superficial fungal infections observed in this study. ${ }^{17,18}$ These findings thus suggest that control of superficial fungal infections among school children can be achieved by improvement in personal hygiene. There is also the need for empowerment of the communities by the government through provision of social amenities and job creation so that the socio-economic status of the parents can improve with resultant better nutrition for the children and improved housing devoid of overcrowding.

\section{Conclusion}

Identified risk factors that predispose to acquiring superficial fungal infections in children were; Attendance of public schools, low socio-economic status of parents, living with either parent rather than with both and poor hygiene and these remained significant factors after binary logistic regression, with low socio-economic status being more or less central to other factors. In order to curtail the spread of SFI among school children, each local gov- ernment authority may provide dermatological services to the schools by ensuring a dermatologist visit to schools at least once every term to identify and treat pupils with SFI, thus reducing the spread of SFI. In the absence of qualified personnel, community health extension workers may be trained on how to identify SFI in pupils for appropriate referrals. Likewise, the school authority should inspect the schoolchildren for good personal hygiene at least once a week and identify any obvious rash on them. They can also promote health seeking behavior among the pupils and their parents/guardians through proper counselling, for instance encouraging hospital visits as needed and lastly, they can give the pupils regular health education on prevention of infection and encourage use of personal clippers and proper grooming of hair.

We hope these findings will assist in reducing the prevalence of SFI among school children in Nigeria as an effort towards promoting holistic health in them.

\section{Study limitation}

In consonance with international research best practices, the use of age and sex matched controls did not allow the researchers to examine the effect of age and sex as independent variables in both the bivariate and multivariate analyses. Thus, the effect of age and sex on development of superficial fungal infections could not be determined from this study.

\section{Conflicts of interest:}

We hereby declare no conflicts of interests as regards this study.

\section{References}

1. Prawer S, Prawer S, Bershow A: Superficial Fungal Infections, in Clinical Dermatology 1st ed. Mc Graw Hill Education, 2013, p71.

2. HavlickovaB, Czaika VA, Friedrich M. Epidemiological trends in skin mycoses worldwide. Mycoses. 2008 Sep;51 Suppl 4:2-15.

3. Seebacher C, Bouchara JP, Mignon B. Updates on the epidemiology of dermatophyte infections. Mycopathologia 2008. Nov-Dec;166:335-352.

4. Rutstein,Shea O, Kiersten J. The DHS Wealth index. DHS Comparative Reports No.6.Calverton, Maryland: ORC Macro. 2004:p1-77.

5. Omisore B, Omisore AG, Abioye-Kuteyi EA. Obesity prevalence and metabolic differences between in-school 
obese and non-obese adolescents in South-Western Nigeria. South African Family Practice. 2015; 57(3): 172-176.

6. Household crowding - Social Report 2010. Available at www.socialreport.msd.govt.nz/economic-standard-living/household-crowding.

7. Bates P. Checklist on hygiene and grooming. Written for Jenny Robb at Mersey Care Trust. 2011: p21.

8. Akinboro AO, Olasode OA, Onayemi O. The pattern, risk factors and clinic-aetiological correlate of Tinea capitis among the children in a tropical community setting of Osogbo, South-Western Nigeria. Afro-Egypt I Infect Endem Dis 2011;1(2):53-64.

9. Metintas S, Kiraz N, Arslantas D, Akgun Y et al. Frequency and risk factors of dermatophytosis in students living in rural areas in Eskisehir, Turkey. Mycopathologia 2004. 157(4): p379-382. PubMed

10. Soyinka F. Epidemiologic study of dermatophyte infections in Nigeria (clinical survey and laboratory investigations). Mycopathologia, 1978 Jul 28; 63(2):99-103.

11. Oyedeji OA, Okeniyi JA, Ogunlesi TA, Onayemi OO, Oyedeji GA, Oyelami OA. Parental factors influencing the prevalence of skin infections and infestations among Nigerian primary school pupils. The Internet Journal of Dermatology. 2006; 3(2).

12. Figueroa JI, Hawranek T, Abraha A, Hay RJ, Tinea capitis in south-western Ethiopia: a study of risk factors for infection and carriage. Int J Dermatol 1997, 36, 661-666 PubMed

13. Ogbonna CIC, Robinson RO, Abubakar JM. The distribution of ringworm infections among primary school children in Jos, Plateau State of Nigeria. Mycopathologia 1985; 89: 101-106.

14. Anosike JC, Keke IR, Uwaezuoke JC, Anozie JC, Obiukwu CE, Nwoke BEB et al. Prevalence and distribution of ringworm infection in primary school children in parts of Eastern, Nigeria. J. of Appl. Sc. and Emviron. Manag. 2005; 9(3): 21-25.

15. Perea S, Jose Ramos M, Garau M, Gonzalez A, Noriega AR, del Palacio A. Prevalence and risk factors of tinea unguium and tinea pedis in the general population in Spain. J Clin Microbiol. 2000, 38 (9) : 3226 PubMed 16. Qadim HH, Golforoushan F, Azimi H, Goldust M. Factors leading to dermatophytosis. Annals of Parasitology 2013, 59(2), 99-102

17. Woolf SH, Braveman P. Where Health Disparities Begin: The Role of Social and Economic Determinants--And Why Current Policies May Make Matters Worse. Health Affairs. 2011; 30 (10): 1852-1859. PubMed 18. World Health organization. A Conceptual Framework for Action on the Social Determinants of Health: Discussion Paper Series on Social Determinants of Health. Available at:http://apps.who.int/iris/bitstre am/10665/44489/1/9789241500852_eng.pdf. 